\title{
Morphology and FT IR spectra of porous silicon
}

\author{
Martin Kopani*, Milan Mikula**, \\ Daniel Kosnac $^{* * *}$, Jan Gregus ${ }^{* * *}$, Emil Pincik ${ }^{* * *}$
}

\begin{abstract}
The morphology and chemical bods of p-type and n-type porous Si was compared. The surface of n-type sample is smooth, homogenous without any features. The surface of p-type sample reveals micrometer-sized islands. FTIR investigation reveals various distribution of $\mathrm{SiO}_{x} \mathrm{H}_{y}$ complexes in both p- and n-type samples. From the conditions leading to porous silicon layer formation (the presence of holes) we suggest both $\mathrm{SiO}_{x} \mathrm{H}_{y}$ and $\mathrm{SiF}_{x} \mathrm{H}_{y}$ complexes in the layer.
\end{abstract}

K e y w ord s: porous silicon, nanoparticles, anodic etching, morphology

\section{Introduction}

Porous silicon is a semiconductor with a high surfaceto-volume ratio produced by electrochemical anodization or chemical etching of silicon. It is a highly Si-based absorbent without anti-reflection coatings with optimal electrical and optical properties. To manufacture this structure, many methods have been developed [1-5]. Improvement of the properties of porous silicon can be accomplished by passivation mechanism. This eliminates defect states, increases the conversion efficiency and creates a stable layer. Oxidation of porous silicon is one of the most suitable passivation procedures [6]. This procedure also creates $\mathrm{Si}$ nanocrystallites covered by $\mathrm{SiO}_{x}$ layer $[7,8]$. The size and structure of nanoparticles is crucial for formation of layers with desired electrical and optical properties. Porous Si layer is created by anodic etching of $\mathrm{Si}$ in an electrochemical cell [9]. The electric field between the cathode (platinum) and anode (silicon) drives holes to the $\mathrm{Si} /$ electrolyte interface. Silicon strongly reacts with HF leading to dissolution of Si. Holes in P-type Si cause etching of the Si layer. Since holes are minority carriers in N-type $\mathrm{Si}$, they do not contribute to Si dissolution [10].

We compare the morphology and infrared spectra of p-type and n-type samples and analyse the processes leading to the formation of various structures by means of Fourier transform infrared spectroscopy and scanning electron microscopy.

\section{Experimental part}

Porous silicon was prepared by electrochemical etching in a teflon cell. Silicon surfaces of P-type boron doped (100) c-Si with resistivity $8-12 \Omega \mathrm{cm}$ and thickness 600
- $650 \mathrm{~nm}$ and n-type antimony doped (100) c-Si with resistivity $0.02 \Omega \mathrm{cm}$ of thickness $500 \mathrm{~nm}$ in $\mathrm{HF}$ vapors were cleaned, immersed in water and pure $\mathrm{CH}_{3} \mathrm{OH}$ (methanol). The silicon wafer creates the anode and a platinum cathode as a mesh is located in the cell cavity. The etching solution $48 \%$ wt HF solution in pure methanol (1:2) is added to the cell cavity for $10 \mathrm{~min}$. The etching current was $50 \mathrm{~mA}$. Finally they were annealed in a chamber with pressure 150 bar, $15 \mathrm{wt} \% \mathrm{~N} 2$, at temperature $250{ }^{\circ} \mathrm{C}$ for $30 \mathrm{~min}$.

Samples were analysed by optical microscope Leica DM 2700 with camera DMC 2900 and scanning electron microscope (SEM) EVO LS 15 (ZEISS) with the accelerating voltage of $3 \mathrm{kV}$. Simultaneous EDX line analysis was performed with AMETEK (EDAX) EDS Element Silicon Drift Detector. The time of spectrum collection was $200 \mathrm{~s}$ with the energy range 0.160 to $8 \mathrm{kV}$. The samples were analysed by FT-IR absorption spectroscopy (ATR-diamond technique) using Digilab Excalibur FTS $3000 \mathrm{MX}$ spectrometer in the range $4000-600 \mathrm{~cm}^{-1}$, resolution of $4 \mathrm{~cm}^{-1}$ and as much as $60 \mathrm{Co-added} \mathrm{scans} \mathrm{for}$ obtaining information on different types of bonding in the structures.

\subsection{Optical and electron microscopy}

Investigation of the n-type sample with optical and scanning electron microscope reveals smooth, homogenous surface without any features.

Investigation of p-type sample with optical microscope reveals three different areas black, white and crossbanding. Morphologies of these areas are different (Fig. 1).

The black area under light microscope reveals an almost smooth morphology (Fig. 2, left). The electron microscope reveals a continuous, unbroken surface consist-

* Institute of Medical Physics, Biophysics, Informatics and Telemedicine, Faculty of Medicine, Comenius University, Sasinkova 4, 811 08, Bratislava, Slovakia, martin.kopani@fmed.uniba.sk, ** Faculty of Chemical and Food Technology of STU, Radlinskeho 9, 812 37 Bratislava, Slovakia, *** Faculty of Mathematics, Physics, Informatics of Comenius University, Bratislava, Slovakia, **** Institute of Physics of SAS, Dúbravská cesta 9,845 11 Bratislava, Slovakia 


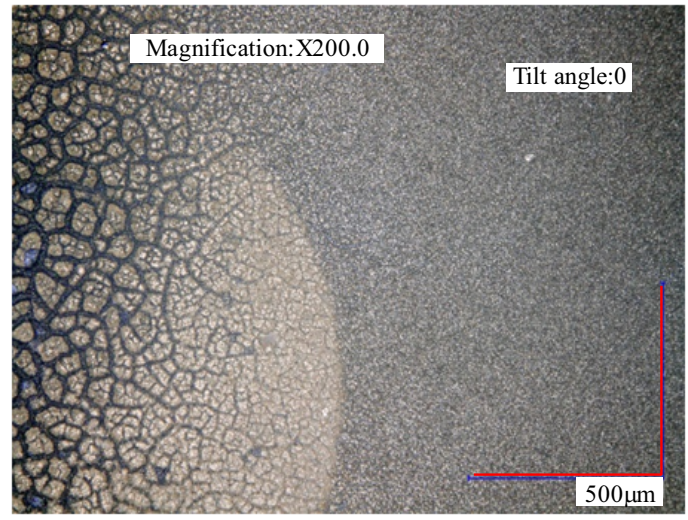

Fig. 1. Image of three areas of p- type sample taken by optical microscopy
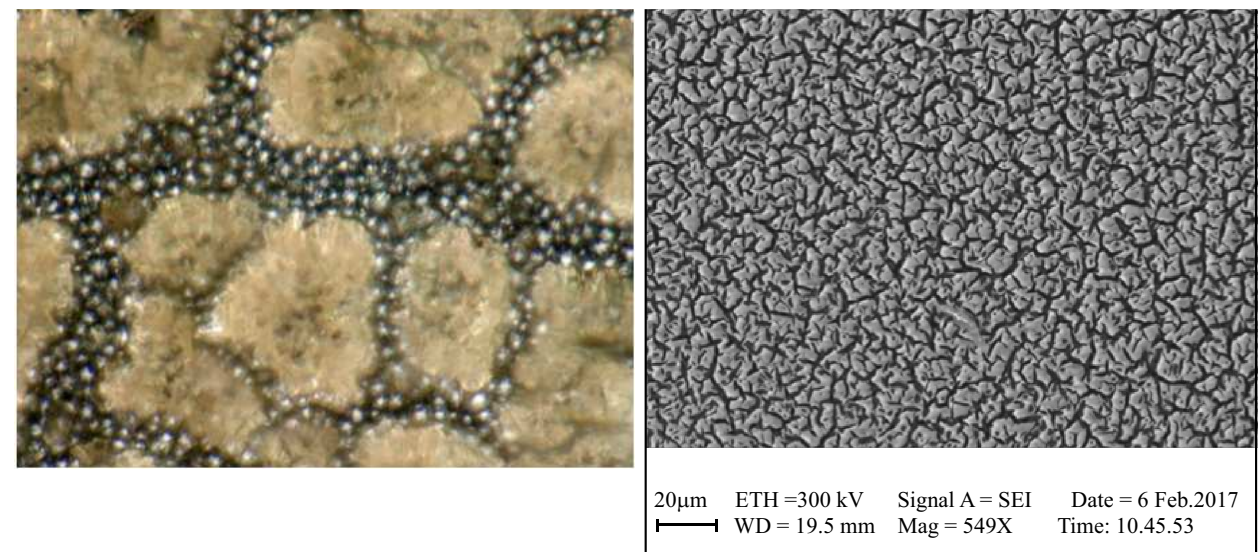

Fig. 2. Image of black area of p- type sample taken by optical microscopy (left) and electron microscopy (right)
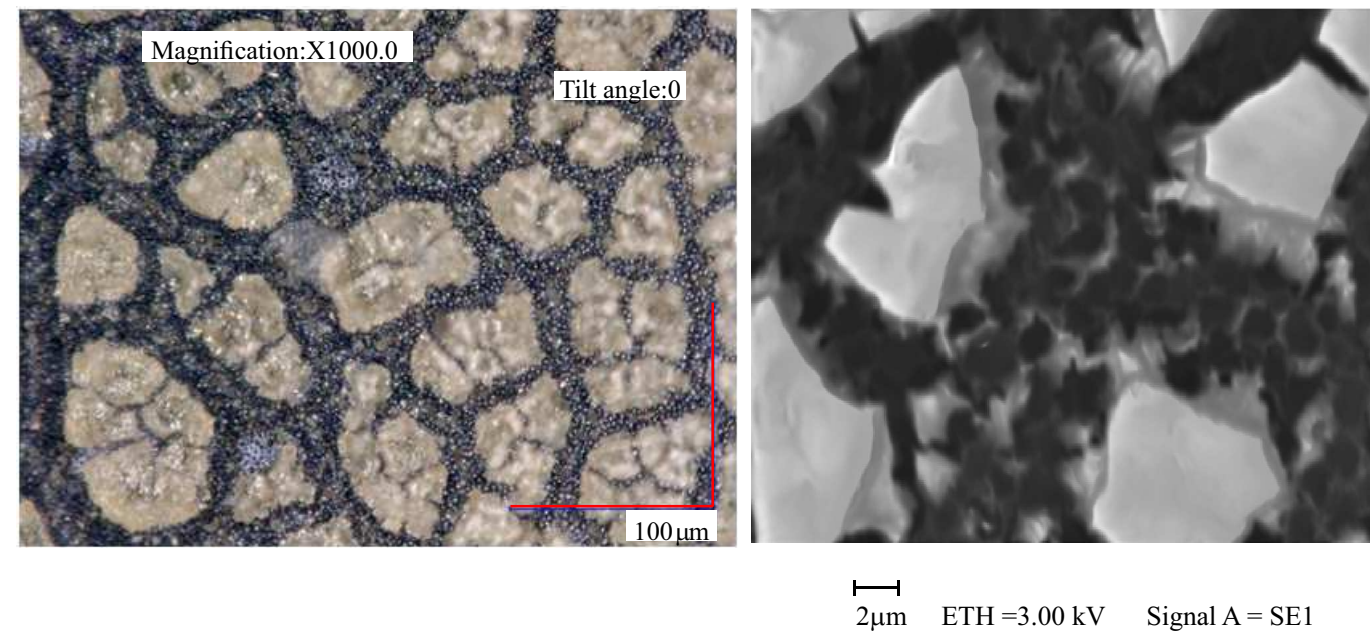

Fig. 3. Image of white area of p- type sample taken by optical microscopy ( left ) and electron microscopy (right)

ing of a large amount of tiny, interconnected islands with small cracks between them (Fig. 2, right).

The white area under light microscope reveals isolated islands with a size of 5 - 10 micrometers (Fig. 3, left). Electron microscope reveals islands with sharp edges. A rough surface is observed between the islands (Fig. 3, right). The crossbanding area shows sporadically isolated islands.
2.2 FT IR (ATR mode) description of the samples

In all investigated samples in the range 750 - 1300 $\mathrm{cm}^{-1}$ four absorption bands are seen: broad absorption from $790 \mathrm{~cm}^{-1}$ to $900 \mathrm{~cm}^{-1}$, unclear absorption band at $905 \mathrm{~cm}^{-1}$ and $936 \mathrm{~cm}^{-1}$ and broad absorption from 980 $\mathrm{cm}^{-1}$ to $1240 \mathrm{~cm}^{-1}$ (Fig. 4, Table 1 ).

Deconvolution was performed of absorption from 790 $900 \mathrm{~cm}^{-1}$ of all samples (Fig. 5). Peak positions after deconvolution for all samples are shown Tab. 2 . 
Table 1. FT IR vibrational frequencies for absorption bands in the range $7501300 \mathrm{~cm}^{-1}$

\begin{tabular}{lcc}
\hline Absorption band & Wavenumber $\left(\mathrm{cm}^{-1}\right)$ & Reference \\
$\mathrm{HSi}(\mathrm{O}) \mathrm{OSi}(\mathrm{O}) \mathrm{H}$ & 835 & {$[11]$} \\
$\mathrm{Si}_{2} \mathrm{~F}_{6} \mathrm{O}$ & 839 & {$[12]$} \\
$\mathrm{Si} \mathrm{H}_{3}$ & 870 & {$[13]$} \\
$\mathrm{HSi}(\mathrm{O})_{2} \mathrm{OSi}(\mathrm{O})_{2} \mathrm{H}$ & 868 & {$[11]$} \\
$\mathrm{HSiH}$ & 901 & {$[14]$} \\
& & {$[15]$} \\
$\mathrm{Si}-\mathrm{H}$ & 905 & {$[16]$} \\
$\mathrm{H}_{2} \mathrm{Si}(\mathrm{O}) \ldots \mathrm{SiH}_{2}$ & 938 & {$[11]$} \\
$\mathrm{H}_{2} \mathrm{Si}(\mathrm{O}) \ldots \mathrm{SiH}_{2}$ & & \\
$\mathrm{H}_{2} \mathrm{Si}(\mathrm{O})_{2} \ldots \mathrm{SiH}_{2}$ & 976 & {$[11]$} \\
$\mathrm{H}_{2} \mathrm{Si}(\mathrm{O})_{2} \ldots \mathrm{Si}_{2}(\mathrm{O})_{2} \mathrm{H}_{2}$ & & \\
$\mathrm{SiF}_{4}$ & 1031 & {$[17]$} \\
$\mathrm{HSi}_{2}(\mathrm{O}) \mathrm{OSiH}$ & 1038 & {$[14]$} \\
$\mathrm{H}_{2} \mathrm{Si}(\mathrm{O})_{-}-2$ dots $\mathrm{SiH}_{2}$ & 1125 & {$[11]$} \\
$\mathrm{SiO}_{4}$ & 1150 & {$[18]$} \\
& & {$[19]$} \\
$\mathrm{Si}-(\mathrm{CH} 3)_{n}$ & 1260,800 & {$[20]$} \\
\hline
\end{tabular}

Table 2. Peak position of absorption $790-900 \mathrm{~cm}^{-1}$ after deconvolution

\begin{tabular}{lcc}
\hline Samples (type) & Fit peak 1 & Fit peak 2 \\
\hline $\mathrm{n}$ & 830 & 865 \\
p, white area & 834 & 872 \\
p, crossbanding area & 836 & 869 \\
p, black & 836 & 874 \\
\hline
\end{tabular}

Table 3. Peak position after deconvolution of absorption $950-1250 \mathrm{~cm}^{-1}$

\begin{tabular}{lcc}
\hline Samples (type) & Fit peak 1 & Fit peak 2 \\
\hline $\mathrm{n}$ & 1042 & 1142 \\
p, white area & 1033 & 1120 \\
p, crossbanding area & 1033 & 1121 \\
p, black area & 1035 & 1147 \\
\hline
\end{tabular}

The amplitude and full width at half maximum (FW $\mathrm{HM}$ ) analysis of the peak around $835 \mathrm{~cm}^{-1}$ for black and white areas of p-type sample shows very similar parameters (slight difference in $\mathrm{SiO}_{x} \mathrm{H}_{y}$ ). A similar effect is observed from the analysis of the second peak around 870 $\mathrm{cm}^{-1}$. The crossbanding area shows the highest amplitude with lowest FWHM.

Deconvolution was conducred of absorption from 950 $1250 \mathrm{~cm}^{-1}$ of all samples (Fig. 6). Peak positions after deconvolution for all samples are shown Tab. 3.

The amplitude and FWHM of the peak around 1026 $\mathrm{cm}^{-1}$ for black and white areas of p-type sample shows the presence of different $\mathrm{SiO}_{x} \mathrm{H}_{y}$ complexes. We cannot rule out the presence of another band in the silicon layer such as Si-CH3.

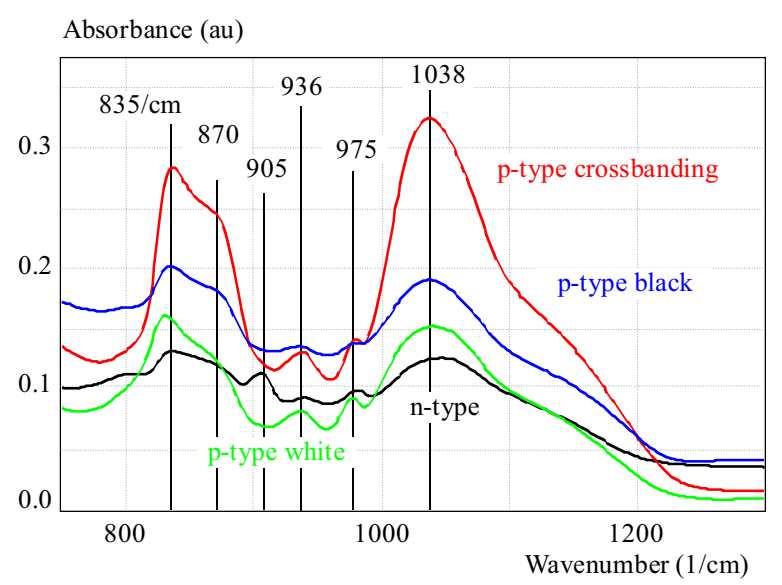

Fig. 4. FTIR spectra of n- and p- type porous silicon structures in the range $7501300 \mathrm{~cm}-1$

\section{Discussion}

Porous silicon is described as a silicon layer with nanocrystallines embedded. Its properties are influenced by many factors such as etching parameters, crystal orientation, dopant type, current density, etching solution and time. Electron microscopy confirmed various structures of silicon layer. It reveals that n-type sample has a smooth, homogeneous surface without any features at the level of nanometers. Only this sample reveals the presence of absorption band assigned to Si-H bonds $\left(905 \mathrm{~cm}^{-1}\right)$ and absorption about $2100 \mathrm{~cm}^{-1}$ assigned to $\mathrm{SiH}_{n}, n=1,2,3$. In addition, presence of $\mathrm{SiO}_{x} \mathrm{H}_{y}$ complexes can be observed. The black area of p-type sample shows a continuous, unbroken surface consisting of large amount of tiny, interconnected islands with small cracks between them. Unlike n-type sample, the ptype sample does not exhibit an absorption band at $905 \mathrm{~cm}^{-1}$. Deconvolution of absorption in the range $790-900 \mathrm{~cm}^{-1}$ shows a shift of absorption to higher wavenumbers of the ptype sample. This observation can be explained by formation of different $\mathrm{SiO}_{x} \mathrm{H}_{y}$ complexes in the p-type sample. These two samples (p- and n-type) show the presence of $\mathrm{SiO}_{4}$ absorption. FWHM of absorption reflects conditions prevailing in the silicon oxide layer such as disorder, mechanical stress, environmental effect, bond angle distortion of bonds or etching process. Compressive stress arising at $\mathrm{Si} / \mathrm{SiO}_{2}$ interfaces is responsible for the changes in IR spectra. From the results of the central force model it is evident that compressive stress causes a decrease in the average tetrahedral SiOSi bond angle whose normal average value is $144^{\circ} \mathrm{C},[21]$. Velde et County [22] investigated high-pressure infrared spectra of amorphous $\mathrm{SiO}_{2}$. They suggest that the absorption peak around 1090 $\mathrm{cm}^{-1}$ is due to compression of the structures and not 

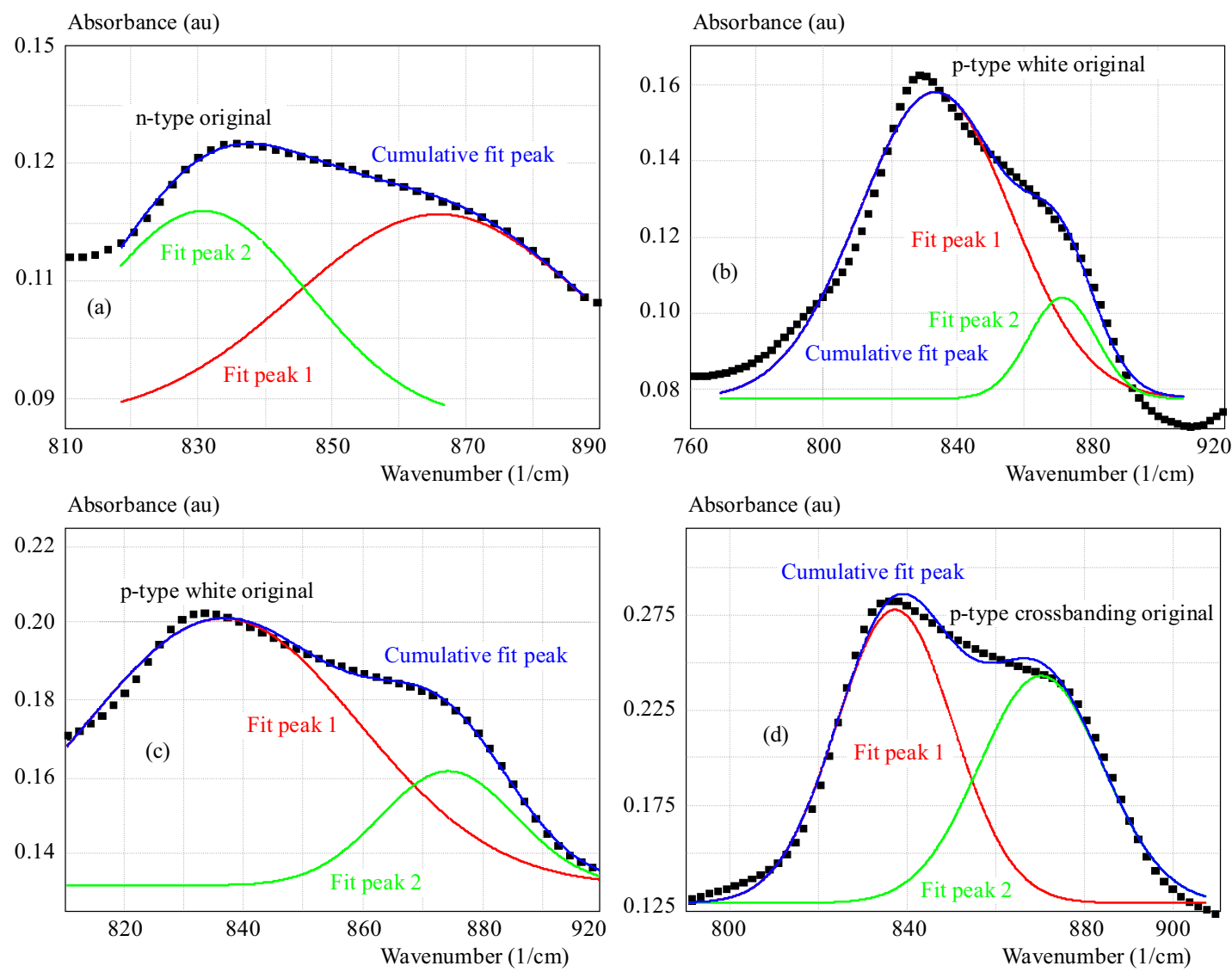

Fig. 5. Results of the analysis of the absorption bands in terms of two gaussian components for p- and n- type samples

due to changes in the bonding of the Si-O. They conclude the presence of at least two arrangements of $\mathrm{SiO}$ ${ }_{4}$ tetrahedrons. These units with $\mathrm{Si}$ as a central tetrahedral atom can be bridged through $\mathrm{O}$ atoms. The absorption peak at around $1090 \mathrm{~cm}^{-1}$ is attributed to five tetrahedral units with four bridging $\mathrm{O}$ atoms. Furukawa et al [23] investigated the peak position in $\mathrm{SiO}_{2}$ thin films prepared by sputtering-type electron resonance methods. They found that at a certain flow rate of oxygen (3-6 sccm) the peak position was $1075 \mathrm{~cm}^{-1}$, but FWHM decreases with an increase of the flow rate of oxygen. During preparation of $\mathrm{Si} / \mathrm{SiO}_{2}$ a thin layer at high temperature goes through phase separation [24]. This process results in formation of $\mathrm{Si}$ nanoclusters in $\mathrm{SiO}_{2}$ films. A shift was observed of the absorption peak from $1025 \mathrm{~cm} 1$ to 1078 cm 1 with increasing annealing temperature from $900{ }^{\circ} \mathrm{C}$ to $1100{ }^{\circ} \mathrm{C}$. Transmission electron microscopy and X-ray diffraction confirm the formation of crystalline Si precipitates within the amorphous $\mathrm{SiO}_{2}$ matrix during annealing. From photoluminescence spectra, Ding et al [25] suggest the presence of nc- $\mathrm{Si} / \mathrm{SiO}_{2}$ interface assigned to absorption at $1083 \mathrm{~cm}^{-1}$. Lisovskii et al [26] investigated the structure of $\mathrm{SiO}_{2}$ thin and ultrathin films before and after bombardment with ${ }^{40} \mathrm{Ar}$ ions of $2.7 \mathrm{keV}$. Deconvolution of Si-O band revealed an bsorption band around $1012 \mathrm{~cm}^{-1}$ and $1038 \mathrm{~cm}^{-1}$. They suggest a modified layer structure with a cluster of $\mathrm{Si}-\mathrm{O}_{x}-\mathrm{Si}_{4-x}$ where $0 \leq x \leq 4$ depending on the depth.
The formation of nanocrystalline Si layer by Lai et al [10] was described

$$
\begin{aligned}
& \mathrm{Si}+4 \mathrm{HF}+4 \mathrm{~h}^{+} \rightarrow \mathrm{SiF}_{4}+4 \mathrm{H}^{+} \\
& \mathrm{SiF}_{4}+2 \mathrm{HF} \rightarrow \mathrm{H}_{2} \mathrm{SiF}_{6}
\end{aligned}
$$

This dissolution of the silicon layer can lead to formation of $\mathrm{SiF}_{x} \mathrm{O}_{y}$ complexes $\left(\mathrm{SiF}_{3} \mathrm{H}, \mathrm{SiF}_{2} \mathrm{H}_{2}, \mathrm{SiFH}_{3}\right)$, $[28,29]$. The presence of these complexes can influence the morphology of the silicon oxide layer. Optical microscopy, electron microscopy and infrared spectroscopy reveal different morphologies and formation of bonds and complexes in p-type and n-type samples. Because the holes influence dissolution of $\mathrm{Si}$ and formation of $\mathrm{SiF}_{x} \mathrm{O}_{y}$ complexes, we suggest that islands of $4 \mathrm{pz}$ samples consist of both $\mathrm{SiO}_{x} \mathrm{H}_{y}$ and $\mathrm{SiF}_{x} \mathrm{O}_{y}$ complexes.

\section{Conclusion}

We compared the morphology and chemical bods in p-type and n-type silicon samples. We found that the surface of n-type sample is smooth, homogeneous without any features. The surface of p-type sample exhibits micrometer-sized islands. FTIR investigation reveals various distribution of $\mathrm{SiO}_{x} \mathrm{H}_{y}$ complexes in both p- and ntype samples. From conditions leading to silicon layer for- 
mation (presence of holes) we suggest both $\mathrm{SiO}_{x} \mathrm{H}_{y}$ and $\mathrm{SiF}_{x} \mathrm{O}_{y}$ complexes in the layer.

\section{Acknowledgements}

This work was partly financially supported by APVV project No. APVV-15-0152 and VEGA No. VEGA2/0076/15. We also thank to Mr Peter Zitto a Mrs Silvia Bacova for technical support.

\section{REFERENCES}

[1] M. Moreno, D. Daineka and P. R. Cabarrocas, "Plasma Texturing for Silicon Solar Cells: From Pyramids to Inverted Pyramidslike Structures", Solar Energy Materials and Solar Cells, vol. 94, no. 5, (2010) 733-737.

[2] Z. Huang, N. Geyer, P. Werner and J. G de Boor, Gösele, U. ", Advanced Materials, vol. 23, no. 02, (2011) 285-308.

[3] C. H. Crouch, J. E. Carey, J. M. Warrender, M. J. Aziz, E. Mazur and F. Y. Génin, "Comparison of Structure and Properties of Femtosecond and Nanosecond LaserStructured Silicon", Applied Physics Letters, vol. 84, no. 11 (2004) 1850-1852,.

[4] Y. Xia, B. Liu, J. Liu, Z. Shen and C. Li, "A Novel Method to Produce Black Silicon for Solar Cells", Solar Energy, vol. 85, no. 07 (2011) 1574-1578.

[5] Y. Xia, B. Liu, S. Zhong and B. Chao, "X-ray Photoelectron Spectroscopic Studies of Black Silicon for Solar Cell", Journal of Electron Spectroscopy and Related Phenomena, vol. 184 (2012), 589-592.

[6] E. Pincik, R. Brunner, H. Kobayashi, M. Mikula, M. Kučera, P, . Jr. Švec, J. Greguš, P. Vojtek, Z. Zábudlá, K. Imamura and M. Zahoran, "About the Optical Properties of Oxidized Black Silicon Structures", Applied Surface Science, vol. 395 (2017), 185-194.

[7] C. K. Wong, H. Wong and V. Filip, "Photoluminescence of Silicon Nanocrystals Embedded Silicon Oxide", , Journal of Nanoscience and Nanotechnology, vol. 9 (2009) 1272-1276.

[8] A. S. Kuznetsov, T. Shimizu, S. N. Kuznetsov, A. V. Klekachev, S. Shingubara, J. Vanacken and V. Moshchalkov, "Origin of Visible Photoluminescence from Arrays of Vertically Arranged Si-Nanopillars Decorated with SiNanocrystals", Nanotechnology, vol. 23, no. 47 (2012), 475709.

[9] M. J. Sailor and E. J. Lee, "Surface Chemistry of Luminescent Silicon Nanocrystallites", Advanced Materials, vol. 9, no. 10 (1997), 783-793.

[10] C. Q. Lai, W. Zheng, W. K. Choi and C. V. Thompson, "Metal Assisted Anodic Etching of Silicon", Nanoscale, vol. 7 (2015), 11123-11134.

[11] Z. H. Wang, T. Urisu, H. Watanabe, K. Ooi, G. R. Rao, S. Nanbu, J. Maki and M. Aoyagi, "Assignment of Surface IR Absorption Spectra Observed the Oxidation Reactions: $2 \mathrm{H}+$ $\mathrm{H} 2 \mathrm{O} / \mathrm{Si}(100)$ and $\mathrm{H} 2 \mathrm{O}+\mathrm{H} / \mathrm{Si}(100)$ ", Surface Science, vol. 57, no. 5 (2005) 330-342.

[12] W. D. Reents, D. L. Wood and A. M. Mujsce, "Impurities Silicon Tetrafluoride Determined by Infrared Spectrometry and FourierTransform MassSpectrometry", Analytical Chemistry, vol. 57 no. 01 (1985), 104109.

[13] D. C. Marra, W. M. M. Kessels, M. C. M. Van de Sanden, Aidy, $\mathrm{K}$ and E. S. Kashefizadeh, "Surface Hydride Composition of Plasma Deposited Hydrogenated Amorphous Silicon: Situ Infrared Study of Ion Flux and Temperature Dependence", Surface Science, vol. 530, no. 102 (2003), 116.

[14] M. K. Weldon, K. T. Queeney, A. B. Gurevich, B. B. Stefanov, Y. J. Chabal and K. Raghavachari, "SiH Bending Modes as a Probe of Local Chemical Structure: Thermal and Chemical
Routes to Decomposition of $\mathrm{H} 2 \mathrm{O}$ on $\mathrm{Si}(100)(2 \times 1)$ ", Journal of Chemical Physics, vol. 113, no. 06 (2000), 2440-2446.

[15] C. Lee, W. Yang and R. G. Parr, "Development of the ColleSalvetti CorrelationEnergy Formula into a Functional of the ElectronDensity", Physical Review, vol. B37, no. 02 (1988), 785-789.

[16] G. Lucovsky, R. J. Nemanich and J. C. Knights, "Structural Interpretation of the Vibration Spectra of aSi:H Alloys", Physical Review, vol. B19, no. 04 (1979), 2064-2073.

[17] A. P. Burtsev, V. Bocharov, V. N. Bocharov, S. K. Ignatov, T. D. Kolomiitsova, P. G. Sennikov, K. G. Tokhadze, L. A. Chuprov, D. N. Shchepkin and O. Schrems, "Integral Intensities of Absorption Bands of Silicon Tetrafluoride the Gas Phase and Cryogenic Solutions: Experiment and Calculation", Optics and Spectroscopy, vol. 98, no. 2 (2005), 227-234.

$18]$ L. He, D. M. Wang and S. Hasegawa, "A Study of PlasmaDeposited Amorphous Siox : $\mathrm{H}(0 \mathrm{i}=\mathrm{x} i=2.0)$ Films Using Infrared Spectroscopy", Journal of NonCrystalline Solids, vol. 261, no. 0103 (2000), 67-71.

[19] P. Lange, U. Schnakenberg, S. Ullerich and H. J. Schliwinski, "Disorder Vitreous $\mathrm{SiO}_{2}$ The Effect of Thermal Annealing on Structural Properties", Journal of Applied Physics, vol. 68, no. 07 (1990), 3532-3537.

[20] J. A. L. Lopez, A. G. Roman, E. G. Barojas, J. F. F. Gracia, J. M. Juarez and J. C. Lopez, "Synthesis of Colloidal Solutions with Silicon Nanocrystals from Porous Silicon", Nanoscale Research Letters, vol. 9, no. 571 (2014), 111.

[21] H. Kobayashi, T.T Sakurai, Y. Yamashita, T. Kubota, O. Maida and M. Takahashi, "Method of Observation of Low Density Interface States by Means of X ray Photoelectron Spectroscopy under Bias and Passivation by Cyanide Ions", Applied Surface Science, vol. 252, no. 21 (2006), 7700-7712.

[22] B. Velde and R. Couty, "Highpressure Infraredspectra of Silica Glass and Quartz", Journal of NonCrystalline Solids, vol. 94, no. 02 (1987), 238-250.

23] K. Furukawa, Y. C. Liu, D. W. Gao, H. K. Nakashima, K. Uchino and K. Muraoka," , Applied Surface Science vol. 121 (1997), 228-232.

$24]$ E. San-Andres, A. Del-Prado, I. Martil, G. Bravo, D. Gonzalezdiaz and F. J. Lopez, "Thermally Induced Modifications on Bonding Configuration and Density of Defects of Plasma Deposited SiOx : H Films", Journal Applied Physics, vol. 92, no. 4 (2002), 1906-1913.

25] L. Ding, T. P. Chen, . Liu, C. Y. Ng, M. Yang, J. I. Wong, F. R. Zhu, M. C. Tan, S. Fung, X. D. Chen and Y. Huang, "Evolution of Photoluminescence Mechanisms of $\mathrm{Si}(+)$ implanted $\mathrm{SiO}$ ${ }_{2}$ Films with Thermal Annealing", Journal of Nanoscience and Nanotechnology, vol. 8, no. 07 (2008) 3555-3560.

26] I. P. Lisovskii, V. G. Litovchenko, V. B. Lozinskii, V. P. Melnik and S. I. Frolov, "Structure of the Modified SurfaceLayer Formed by IonBombardment of $\mathrm{SiO}_{2}$ Films", Thin Solid Films, vol. 247, no. 02 (1994), 264-270.

27] J. F. D'Eu, J. Demaison and H. Burger, "MillimeterWave and HighResolution FTIR Spectroscopy of SiH2F2: The Ground and $\mathrm{v} 4=1$ States", Journal of Molecular Spectroscopy, vol. 218, no. 1 (2003), 12-21.

28] H. Bürger and P. Schultz, "The HighResolution Fourier Transform Infrared Spectrum of H3SiF near $2200 \mathrm{~cm}^{-1}$ : Rovibrational Analysis of the Fundamentals v1 and v4 and Their Perturbers 3v61 and 3v63", Journal of Molecular Spectroscopy, vol. 125, no. 1 (1987), 140-153.

$29]$ J. A. L. Lopez, A. G. Roman, E. G. Barojas, J. F. F. Gracia, J. M. Juarez and J. C. Lopez, "Synthesis of Colloidal Solutions with Silicon Nanocrystals from Porous Silicon", Nanoscale Research Letters, vol. 9, no. 571 (2014), 111.

Received 23 April 2017 